\title{
Development of high-strength concrete with the addition of a universal superplasticizer
}

\author{
Aida Barkhanadzhyan ${ }^{1 *}$, Alimjon Riskulov ${ }^{1}$, Maksud Karimov $^{2}$, Ravshan Khakimov ${ }^{1}$, and \\ Botir Ibragimov ${ }^{1}$ \\ ${ }^{1}$ Tashkent State Transport University, Tashkent, Uzbekistan \\ ${ }^{2}$ JSC "Uzkimyosanoat", Tashkent, Uzbekistan
}

\begin{abstract}
Automobile roads perform a particularly important, responsible function in the movement of every automobile, transport equipment. The quality of automobile roads determines the reliability of road construction and automotive equipment, the resource of their work, and, most importantly, ensuring traffic safety. However, the construction of roads and construction methods with the expiration of a certain time undergo significant changes associated with the intensive development of road transport, road construction equipment, an increase in the intensity and flow of traffic. In this regard, there is a need to build high-quality roads and cover roads with durable concrete, which can be achieved by upgrading with composite chemical additives in the composition of concrete - a modernized superplasticizer. The object of this work is a superplasticizer for producing wear-resistant concrete. The introduction of a superplasticizer into the composition of concrete makes it possible to obtain especially strong concrete with an increased service life, which in turn will significantly reduce material costs for raw materials, repair work, and labor resources. The purpose of this study is to obtain a highly effective superplasticizer and particularly durable wear-resistant concrete for road surfaces. To achieve this goal, it is necessary to solve the following tasks:

- prepare raw materials, develop an optimal component composition and obtain a superplasticizer;

- in laboratory conditions to obtain a prototype of concrete;

- determine the quality indicators of the resulting concrete by GOST;

- to conduct pilot tests for implementation in production.
\end{abstract}

\section{Introduction}

The research of many scientists is devoted to obtaining concrete for covering automobile roads. In the works of Kramar L.Yu. the choice of building material for the construction of motor roads has been studied [1-5]. Usually, when studying the effect of chemical additives on cement stones' physical and mechanical properties, the water-cement ratio of the normal density of the cement paste is chosen $[6,7]$. The water-cement ratio of the normal density of the cement paste fluctuates in the range of $0.2-0.3$. With normal cement paste density,

\footnotetext{
"Corresponding author: bal-37@mail.ru
} 
the change in the water-cement ratio, with the addition of plasticizing additives, is insignificant. Under these conditions, the plasticizing efficiency of plasticizers depends most of all on the measurement accuracy [8]. Therefore, a water-cement ratio of 0.43 was chosen.In laboratory conditions, we prepared concrete prototypes and synthesized superplasticizers to increase the wear resistance and strength of concrete. The effect of plasticizing additives on cement stones' physical and mechanical properties has been studied [9-11].

For the preparation of concretes, Portland cement PC500 D0, PC400 D0, PC400 D20, products of JSC Akhangarancement, high-aluminate cement, and stucco were used. Portland cement grades PC500 D0, PC400 D0, PC400 D20 have the following chemical and mineralogical composition (Table 1,2):

Table 1. The chemical composition of the used cements

\begin{tabular}{|c|c|c|c|c|c|c|c|c|c|}
\hline № & Type of & \multicolumn{8}{|c|}{ Chemical composition, \% } \\
\cline { 3 - 10 } & cement & $\mathrm{SiO}_{2}$ & $\mathrm{Al}_{2} \mathrm{O}_{3}$ & $\mathrm{Fe}_{2} \mathrm{O}_{3}$ & $\mathrm{CaO}$ & $\mathrm{MgO}$ & $\mathrm{SO}_{3}$ & $\mathrm{R}_{2} \mathrm{O}$ & $\mathrm{CaO}_{\text {cв }}$ \\
\hline 1 & PC400 D0 & 22.55 & 4.75 & 4.7 & 65.04 & 1.73 & 0.21 & 0.62 & 0.16 \\
\hline 2 & PC400 D20 & 22.1 & 5.0 & 9.0 & 64.0 & 0.92 & 0.94 & 1.01 & 0.27 \\
\hline 3 & PC500 D0 & 21.75 & 4.91 & 4.62 & 66.2 & 1.73 & 0.21 & 0.62 & 0.16 \\
\hline
\end{tabular}

Table 2. Mineralogical composition of the used cements

\begin{tabular}{|c|c|c|c|c|c|c|c|}
\hline \multirow{2}{*}{$N$} & \multirow{2}{*}{$\begin{array}{c}\text { Type of } \\
\text { cement }\end{array}$} & \multicolumn{4}{|c|}{ Main mineral content } & \multicolumn{2}{c|}{ Content of additives } \\
\cline { 3 - 8 } & $\mathrm{C}_{3} \mathrm{~S}$ & $\mathrm{C}_{2} \mathrm{~S}$ & $\mathrm{C}_{3} \mathrm{~A}$ & $\mathrm{C}_{4} \mathrm{AF}$ & Gliezh & $\mathrm{SO}_{3}$ \\
\hline 1 & PC400 D0 & 64.21 & 13.11 & 6.24 & 11.9 & 0 & 2.10 \\
\hline 2 & PC400 D20 & 62.03 & 15.26 & 6.49 & 11.93 & 19.0 & 2.0 \\
\hline 3 & PC500 D0 & 67 & 14 & 4 & 14 & - & 0.09 \\
\hline
\end{tabular}

\section{Methods}

In this work, the physicochemical properties of binders on mortars and concretes were studied. The rheological properties of cement pastes were determined using a mini-cone, following the standard procedure GOST 310.3-76. The method is based on measuring the diameter of the spreading of cement paste under the action of gravity. The effect of superplasticizers on cement slurries was investigated. To compare the qualities of superplasticizers, the well-known superplasticizers Melment (BASF Construction Additives) and Relamix (Polyplast) were taken. The additives were introduced in the form of aqueous solutions. The concentration of additives was calculated as a percentage of dry matter based on the weight of the dispersed phase. The additives were introduced with mixing water; measurements were carried out after two minutes of stirring the suspension.

The cement paste's normal density and setting time were determined using a Vic's device following GOST 310.3-76. The effect of superplasticizers on the strength of cement stone was determined on specimens $2 \times 2 \times 2 \mathrm{~cm}$ in size, which hardened under normal conditions, and then tested for compression at 28 days of age.

Tests of the effect of additives on the mobility of concrete mixtures were carried out following GOST 10181.1-2000. The mobility of the concrete mixture was determined using a standard cone. The cone was filled with the concrete mixture under study; the mixture was compacted by sticking at least 25 times in each of the three layers as the cone was filled. After raising the cone, the value of the cone slump was measured using a ruler with an accuracy of $0.5 \mathrm{~cm}$. The effect of additives on the compressive strength of concrete was determined following GOST 10180-90 using a P-50X21856 GOST 8905-73 press. The compressive strength of concrete was determined on concrete cubes with dimensions of $10 \times 10 \times 10 \mathrm{~cm}$ at 28 days of age. Samples were made in series of 6 samples each. 
Compaction of the concrete mixture was carried out on a vibration platform of type $435 \mathrm{~A}$. The concrete mixture with a cone draft $<12 \mathrm{~cm}$ was compacted by bayonetting.

The study of concrete frost resistance was carried out on concrete samples $10 \times 10 \times 10 \mathrm{~cm}$ in size by the accelerated method according to GOST 10060.0-95. The concrete grade was established depending on the number of freezing and thawing cycles that the samples withstood without reducing the compressive strength by more than $5 \%$ compared to the strength of the control samples at an equivalent age, and the weight loss did not exceed 3\%.

\section{Results and Discussion}

The most important property for plasticizing additives is considered to be the spreadability of mortars. Plasticizers should improve the rheological properties of mortars, but at the same time, they should not worsen the strength and other physical and mechanical properties of cement systems [12-15]. The test results of cement pastes with a plasticizing additive based on polyhydric alcohols are shown in Table 3.

Table 3. Test results of cement pastes with a plasticizing additive based on polyhydric alcohols

\begin{tabular}{|l|c|c|c|c|c|}
\hline № & $\begin{array}{c}\text { The amount } \\
\text { of cement, g }\end{array}$ & $\begin{array}{c}\text { Additive amount based on } \\
\text { cement weight, \% }\end{array}$ & W/C ratio & $\begin{array}{c}\text { Spread, } \\
\mathrm{cm}\end{array}$ & $\begin{array}{c}\text { Average } \\
\text { density, g/cm }\end{array}$ \\
\hline \multicolumn{5}{|c|}{ glycerin based } \\
\hline 1 & 100 & - & 0.43 & 6 & 1.950 \\
\hline 2 & 100 & 0.2 & 0.43 & 8 & 1.900 \\
\hline 3 & 100 & 0.5 & 0.43 & 11 & 1.880 \\
\hline 4 & 100 & 0.8 & 0.43 & 11,5 & 1.850 \\
\hline 5 & 100 & 1 & 0.43 & 12 & 1.800 \\
\hline \multicolumn{5}{|c|}{ pentaerythritol-based } \\
\hline 1 & 100 & - & 0.43 & 6 & 1.950 \\
\hline 2 & 100 & 0.2 & 0.43 & 8,5 & 1.950 \\
\hline 3 & 100 & 0.5 & 0.43 & 10.8 & 1.900 \\
\hline 4 & 100 & 0.8 & 0.43 & 11 & 1.855 \\
\hline 5 & 100 & 1 & 0.43 & 12 & 1.850 \\
\hline \multicolumn{5}{|c|}{ ethylene glycol based } \\
\hline 1 & 100 & - & 0.43 & 6 & 1.940 \\
\hline 2 & 100 & 0.2 & 0.43 & 9 & 1.915 \\
\hline 3 & 100 & 0.5 & 0.43 & 10.5 & 1.895 \\
\hline 4 & 100 & 0.8 & 0.43 & 11 & 1.850 \\
\hline 5 & 100 & 1 & 0.43 & 11 & 1.755 \\
\hline \multicolumn{5}{|c|}{ diethylene glycol based } \\
\hline 1 & 100 & - & 0.43 & 6 & 1.960 \\
\hline 2 & 100 & 0.2 & 0.43 & 7,5 & 1.940 \\
\hline 3 & 100 & 0.5 & 0.43 & 9 & 1.880 \\
\hline 4 & 100 & 0.8 & 10 & 1.850 \\
\hline 5 & 100 & 1 & 0.43 & 11 & 1.755 \\
\hline \multicolumn{5}{|c|}{}
\end{tabular}

As can be seen from Table 3, relatively high strength is obtained with the introduction of a plasticizing additive based on diethylene glycol in an amount of $0.8 \%$.

The effect of a plasticizing additive (based on polyhydric alcohols) on the W/C ratio and strength of the cement system was also studied [16-18]. 
Table 4. Effect of a plasticizing additive based on polyhydric alcohols on the $\mathrm{W} / \mathrm{C}$ ratio and strength of the cement system

\begin{tabular}{|c|c|c|c|c|}
\hline № & $\begin{array}{l}\text { The amount } \\
\text { of cement, } g\end{array}$ & $\begin{array}{c}\text { Additive amount based on cement } \\
\text { weight, } \%\end{array}$ & $\mathrm{~W} / \mathrm{C}$ ratio & $\begin{array}{l}\text { Strength, } \\
\mathrm{MPa}\end{array}$ \\
\hline \multicolumn{5}{|c|}{ glycerin based } \\
\hline 1 & 100 & - & 0.24 & 18 \\
\hline 2 & 100 & 0.2 & 0.23 & 24 \\
\hline 3 & 100 & 0.5 & 0.23 & 29 \\
\hline 4 & 100 & 0.8 & 0.225 & 33 \\
\hline 5 & 100 & 1 & 0.22 & 36 \\
\hline \multicolumn{5}{|c|}{ pentaerythritol-based } \\
\hline 1 & 100 & - & 0.24 & 18 \\
\hline 2 & 100 & 0.2 & 0.23 & 21 \\
\hline 3 & 100 & 0.5 & 0.23 & 26 \\
\hline 4 & 100 & 0.8 & 0.22 & 30 \\
\hline 5 & 100 & 1 & 0.22 & 38 \\
\hline \multicolumn{5}{|c|}{ ethylene glycol based } \\
\hline 1 & 100 & - & 0.24 & 18 \\
\hline 2 & 100 & 0.2 & 0.23 & 24 \\
\hline 3 & 100 & 0.5 & 0.23 & 26 \\
\hline 4 & 100 & 0.8 & 0.23 & 30 \\
\hline 5 & 100 & 1 & 0.225 & 27 \\
\hline \multicolumn{5}{|c|}{ diethylene glycol based } \\
\hline 1 & 100 & - & 0.24 & 18 \\
\hline 2 & 100 & 0.2 & 0.23 & 25 \\
\hline 3 & 100 & 0.5 & 0.23 & 25 \\
\hline 4 & 100 & 0.8 & 0.225 & 26 \\
\hline 5 & 100 & 1 & 0.225 & 25 \\
\hline
\end{tabular}

The table shows that the plasticizing additive based on glycerin compared with the rest of the obtained plasticizing additives showed the best result.

At the same time, it should be noted that glycerin is a local raw material and is produced in the Republic of Uzbekistan; therefore, a plasticizing additive based on glycerin can be recommended for use in the production of concrete.

Table 4 also shows that an increase in the amount of a plasticizing additive based on pentaerythritol decreases the strength of the cement stone. The same situation is observed when adding a plasticizing additive based on ethylene glycol. The strength of the cement stone with the addition of this additive in an amount of $0.8 \%$ reaches $30 \mathrm{MPa}$. When adding plasticizing additives based on glycerin and pentaerythritol, the strength of the cement stone increases with an increase in the number of additives, i.e. it can be assumed that the obtained plasticizing additives based on ethylene glycol and pentaerythritol have a small plasticizing effect [19-22].

We have synthesized superplasticizer SJ-1 based on polycarboxylates. Their difference from previously developed superplasticizers lies in the mechanism of their action. Unlike those developed earlier, superplasticizers based on polycarboxylate esters have a spatial molecular structure with branched side chains. This contributes to more efficient dispersion of cement floccules due to the steric effect and also allows water access to clinker minerals. The obtained superplasticizer SJ-1 has a good water-reducing effect. This makes polycarboxylate-based superplasticizers the most promising modifier [23-26].

Investigation of the effect of superplasticizer SJ-1 on cement stones' physical and mechanical properties is described below. For testing the superplasticizer, Portland cement PC 400 D20, gypsum and high-aluminate cement (white cement, high-alumina cement) were selected as dry building materials (Table 5). 
Table 5. Test results of cement pastes (PC400 D0, PC400 D20, PC500 D0) with synthesized superplasticizer SJ-1

\begin{tabular}{|c|c|c|c|c|c|c|c|c|c|}
\hline \multirow[b]{2}{*}{ № } & \multirow{2}{*}{$\begin{array}{l}\text { The } \\
\text { amount } \\
\text { of } \\
\text { cement, } \\
\text { g }\end{array}$} & \multirow{2}{*}{$\begin{array}{c}\text { Additive } \\
\text { amount } \\
\text { based on } \\
\text { cement } \\
\text { weight, } \\
\%\end{array}$} & \multirow[b]{2}{*}{$\begin{array}{l}\mathrm{W} / \mathrm{C} \\
\text { ratio }\end{array}$} & \multicolumn{3}{|c|}{ Average density, $\mathrm{g} / \mathrm{cm}^{3}$} & \multicolumn{3}{|c|}{$\begin{array}{c}\text { Strength after } 28 \text { days, } \\
\mathrm{MPa}\end{array}$} \\
\hline & & & & ষ্ঠ & 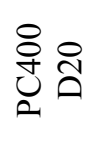 & \begin{tabular}{l}
8 \\
\hdashline \\
\hdashline \\
\hdashline
\end{tabular} & ষ̊ & 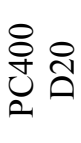 & $\begin{array}{l}8 \\
: \\
0 \\
0\end{array}$ \\
\hline 1 & 100 & - & 0.24 & 2.235 & 2.225 & 2.235 & 43.75 & 25 & 24.5 \\
\hline 2 & 100 & 0.1 & 0.24 & 2.241 & 2.232 & 2.241 & 45 & 31.5 & 33.75 \\
\hline 3 & 100 & 0.2 & 0.23 & 2.243 & 2.233 & 2.243 & 48 & 36,2 & 35 \\
\hline 4 & 100 & 0.5 & 0.22 & 2.25 & 2.23 & 2.25 & 52.5 & 42 & 38 \\
\hline 5 & 100 & 0.8 & 0.21 & 2.25 & 2.25 & 2.25 & 59 & 46 & 43 \\
\hline 6 & 100 & 1 & 0.21 & 2.29 & 2.26 & 2.292 & 65.6 & 48 & 45 \\
\hline
\end{tabular}

As can be seen from Table 5, in most cases, a decrease in the $\mathrm{W} / \mathrm{C}$ ratio leads to an increase in the strength of the cement stone, which indicates the high efficiency of the superplasticizer SJ-1.

\section{Conclusions}

Based on the work performed, the following conclusions can be drawn:

1. Received samples of concrete mix are made based on local raw materials;

2. Synthesized superplasticizer SJ-1 based on polycarboxylates to obtain extra strong concrete;

3. Studied the main properties of the superplasticizer and its effect on cement stones;

4. It has been established that the strength properties of concrete depend on the watercement ratio, on the amount of superplasticizer. With an increase in the concentration of the superplasticizer from 0.2 to $1 \%$, the strength of concrete increases from 48 to $65.6 \mathrm{MPa}$

\section{References}

1. Borisov B.I. On the classification of the causes of road traffic accidents // Vestnik SSTU. -2013. -N-2 (71). Issue 2.- P. 366-369.

2. S. Ikehaga, "Active Suspension Control of Ground Vehicle based on a Full-Vehicle Model", American Control Conference, pp.4019-4024, 2000.

3. Guo L, Ge PS, Yue M, et al. Lane changing trajectory planning and tracking controller design for intelligent vehicle running on curved road. Math Probl Eng 2014; 2014 : 19

4. Yoshida H, Shinohara S and Nagai M. Lane change steering maneuvers using model predictive control theory. Veh Syst Dynam 2008; 46: 669-681.

5. Motor vehicles. Controllability and stability. Test methods. Interstate standards. GOST 31507-2012. M.: Standartinform, 2013.

6. ISO 3888-1:1999 Passenger cars - Test track for a severe lane-change manoeuvre Part 1: Double line-change.

7. ISO 3888-2:2002 Passenger cars - Test track for a severe lane-change manoeuvre Part 2: Obstacle avoidance.

8. Antonov D.A. The theory of stability of motion of multi-axle vehicles. M.: Mashinostroenie, $1987.216 \mathrm{p}$. 
9. Allen, R.W., Christos, J.P., etc., 2002, "Driver/Vehicle Modeling and Simulation", SAE Transations Paper No. 2002-01-1568.

10. Allen, R.W., Rosenthal, T.J., etc., 1999, “Computer Simulation Analysis of Light Vehicle Lateral/Directional Dynamic Stability”, SAE Transactions Paper No. 199901-0124.

11. Bernard, J., Gruening, J., and Hoffmeister, K., 1998, "Evaluation of Vehicle/Driver Performance Using Genetic Algoritms", SAE Transactions Paper No. 980227.

12. U.S. Department of Transportation NHTSA: Traffic Safety Facts 2002. Washington DC 2004.

13. Flystra, D., Lasdon, L., Watson, J. and Waren, A., 1998, "Design and Use of the Microsoft Excel Solver", Interfaces, 28, No. 5, pp. 29-55.

14. Fraichard, T., and Scheuer, A., 2004, "From Reeds and Shepp's to ContinuousCurvature Paths", IEEE Transactions on Robotics, 20, NO. 6, pp. 1025-1035.

15. Forkenbrock, G.J., Garrott, W.R., 2002, "Light Vehicle Dynamic Rollover Propensity Phases IV, V, and VI: Research Activities", Unpublished NHTSA presentation

16. Forkenbrock, G.J., Heitz, M., etc., 2003, “An Experimmental Examination of J-Turn and Fishhook Maneuvers That May Induce On-Road, Untripped, Light Vehicle Rollover", SAE Transactions Paper No. 2003-01-1008.

17. Forkenbrock, G.J., Heitz, M, etc., 2003, “An Experimmental Examination of Double Lane Change Maneuvers That May Induce On-Road, Untripped, Light Vehicle Rollover", SAE Transactions Paper No. 2003-01-1009.

18. Forkenbrock, G.J., O’Harra, B.C., Elsasser D. 2003, “An Experimental Examination of Light Vehicles Using Test Maneuvers That May Induce On-Road, Untripped Rollover and a Discussion of NHTSAs Refined Test Procedures -Phases VI and VII of NHTSAs Light Vehicle Rollover Research Program", U.S. Department of Transportation Report No. DOT HS 809547.

19. Frimberger, M., Wolf, F., Scholpp, G. etc., 2000, "Influences of Parameters at Vehicle Rollover", SAE Transactions Paper No. 2000-01-2669.

20. Gillespie, T.D. 1992, Fundamentals of Vehicle Dynamics, Society of Automotive Engineers, Warrendale, PA.

21. Langer, W., 1995, "Validation of Flat Surface Roadway Technology", Society of Automotive Engineers Paper No. 950310.

22. Langer, W., 1996, "Vehicle Testing With Flat Surface Roadway Technology", Society of Automotive Engineers Paper No. 960731.

23. Lasdon, L.S. and Smith, S., 1992, "Solving large sparse nonlinear programs using GRG”, ORSA Journal on Computing, Vol. 4, No. 1, pp. 2-15

24. Marine, M.C., Wirth, J.L. and Thomas, T.M., 1999, "Characteristics of On-Road Rollovers", SAE Transactions Paper No. 1999-01-0122. 